\title{
EFEITO DA ROTAÇÃO DE CULTURAS, DA MONOCULTURA E DA DENSIDADE DE PLANTAS NA INCIDÊNCIA DAS PODRIDÕES DA BASE DO COLMO E NO RENDIMENTO DE GRÃOS DO MILHO
}

\author{
EIDI ALFREDO DENTI ${ }^{1} \&$ ERLEI MELO REIS ${ }^{2}$ \\ ${ }^{1}$ Escola Agrotécnica Federal de Sertão, Cx. Postal 21, CEP 99170-000, Sertão, RS; \\ ${ }^{2}$ Universidade de Passo Fundo, Cx. Postal 611, CEP 99001-970, Passo Fundo, RS, e-mail:erleireis@ uol.com.br
}

(Aceito para publicação em 13/07/2001)

Autor para correspondência: Erlei Melo Reis

DENTI, E.A. \& REIS, E.M. Efeito da rotação de culturas, da monocultura e da densidade de plantas na incidência das podridões da base do colmo e no rendimento grãos do milho. Fitopatologia Brasileira 26:635-639. 2001.

\section{RESUMO}

Quantificou-se neste trabalho o efeito da rotação de culturas, da monocultura e da densidade de plantas na incidência de doenças e no rendimento de grãos, associados às podridões da base do colmo (PBC) do milho (Zea mays), em experimentos de campo conduzidos na área experimental da Universidade de Passo Fundo (RS) durante a safra 1998/99. Utilizou-se o genótipo Pioneer 3071, semeado em parcelas de quatro linhas de $5 \mathrm{~m}$ distribuídas em blocos ao acaso e cinco tratamentos (30, 40, 50 ,60, e 70 mil plantas ha ${ }^{-1}$ ) com quatro repetições. As avaliações da incidência das PBC foram realizadas a cada sete dias. A incidência das PBC variou de zero a $12,9 \%$ sob rotação de culturas e de $1 \mathrm{a} 46,8 \%$ em monocultura. Os fungos Diplodia maydis $(8,4 \%)$ e $D$. macrospora $(4,8 \%)$ foram as espécies isoladas com maior freqüência de colmos sintomáticos em monocultura. $\mathrm{Na}$ área de rotação de culturas, a maior incidência foi de D. maydis, com 3,4\% seguida de D. macrospora, com 3,3\%.

Palavras-chave: Sistemas de cultivo, população de plantas, Zea mays.

\section{ABSTRACT \\ Effects of crop rotation, monoculture and plant density on the incidence of stalk rot and on corn yield}

The effect of crop rotation, monoculture, and plant stand on the incidence of corn (Zea mays) stalk rot and the associated yield reduction was examined in two field experiments conducted at the Universidade de Passo Fundo during the 1998/99 cropping season. The corn hybrid Pioneer 3071 was sown in four rows $(5 \mathrm{~m}$ long) per plot. The plots were arranged in a randomized block design with five treatments $(30,40,50,60$, and 70 thousand plants/ha) and four replications. Stalk rots were assessed weekly from 18 February to 8 April 1999. The disease incidence ranged from zero to $12.9 \%$ in the crop rotation area and from 1 to $46.9 \%$ under monoculture of corn. Diplodia maydis and D. macrospora were the fungal species most isolated from symptomatic stalks in both monoculture (8.4 and $4.8 \%$ ) and crop rotation (3.4 and $3.3 \%)$ systems.

\section{INTRODUÇÃO}

O milho (Zea mays L.) é um dos cereais mais importantes no segmento produtivo agropecuário. O Brasil é o terceiro maior produtor mundial, com uma produção de 32 milhões de toneladas na safra 1998/99, tendo o Rio Grande do Sul, na média dos últimos cinco anos, uma produção de 4,21 milhões de toneladas (Recomendações, 1999). Entre os fatores que limitam o rendimento da cultura enquadram-se os agentes bióticos, dos quais destacam-se as doenças que causam as podridões da base do colmo (PBC) do milho. Por PBC entende-se a presença de sintomas e/ou sinais de patógenos na superfície da epiderme e/ou subepidérmicos e a menor resistência da base do colmo, nos primeiro e segundo entre-nós longos acima da superfície do solo. Tais alterações comprometem a translocação de água e de nutrientes do solo para os órgãos aéreos da planta, afetando o rendimento potencial e a qualidade do grão (Christensen \& Wilcoxson, 1966:Shurtleff, 1992). Para Agrios (1997), as podridões do colmo do milho têm sido apontadas como as doenças mais preocupantes pelo seu efeito destrutivo. O cultivo de milho sob monocultura favorece o aumento da incidência das PBC e do dano, na medida que a incidência da doença apresenta uma relação direta com a quantidade de restos culturais infetados presentes na superfície do solo (Byrnes \& Carrol, 1986; Del Rio \& Zúgia, 1991) e, consequentemente, com a maior taxa de sobrevivência dos fitopatógenos associados aos restos culturais (Snyman \& Wehner, 1988). Considera-se também como fator relevante na ocorrência das $\mathrm{PBC}$ do milho a densidade de plantas (Machado, 1994; Agrios, 1997), aliada 
a um desequilíbrio nutricional, a competição predispõe as plantas às PBC (Shurtleff, 1992).

A literatura nacional tem relatado que os principais fungos que ocorrem em milho no Brasil, atacando o seu colmo, são:Colletotrichum graminicola (Ces) G. V. Wils:Diplodia maydis (Berk.) sin. D. zeae (Schw.) Lev. Diplodia macrospora Earle; Fusarium graminearum Schwabe (Gibberella zeae Schw.) Petch, Fusarium moniliforme Sheldon (Gibberella fujikuori Sawada); Fusarium moniliforme var. subglutinans (Wr. \& Reink.) (Gibberella fujikuori var subglutinans Edwards) (Pereira \& Pereira, 1976; Balmer \& Pereira, 1987; Reis \& Casa, 1996).

Nos Estados Unidos, foram relatados danos causados pelas podridões do colmo do milho de 10 a $20 \%$ em híbridos suscetíveis e em outros países de 25 a $30 \%$, chegando a $50 \%$ em algumas regiões (Shurtleff, 1992). No Brasil, a ocorrência é freqüente e danos econômicos em lavouras de milho tem sido apontados (Balmer \& Pereira, 1987; Reis \& Casa, 1996). Embora pouca atenção tenha sido dada a quantificação de danos, incidência entre 15 a $85 \%$ e danos de 12 a $40 \%$ foram relatadas por Nazareno (1989). Recentemente, Reis et al. (1998) e Denti et al. (1999) quantificaram a incidência de 4 a $72 \%$ e danos entre 0,67 a $50 \%$, dependendo do ano, do local e do genótipo.

Neste trabalho, formulou-se a hipótese de que os danos das PBC são passíveis de quantificação e de que a incidência das $\mathrm{PBC}$ do milho é influenciada pela presença de restos culturais na superfície do solo como fonte de inóculo, rotação de culturas, monocultura, densidade de plantas e pelas espécies de cobertura de solo utilizadas no inverno. O objetivo deste trabalho foi quantificar os efeitos da monocultura de milho, da rotação de culturas e da população de plantas na incidência e nos danos causados pelas PBC e também identificar as espécies de fungos envolvidas com as PBC nos dois sistemas de cultivo.

\section{MATERIAL E MÉTODOS}

Na safra 1998/99, foram instalados dois experimentos, um no sistema de rotação de culturas e outro em monocultura de milho na área experimental da Universidade de Passo Fundo, RS. O município de Passo Fundo está situado a uma altitude aproximada de $700 \mathrm{~m}$ acima do nível do mar e o solo pertence à unidade de mapeamento Passo Fundo, sendo caracterizado como latossolo vermelho escuro distrófico (Brasil, 1973). A área de rotação de culturas foi cultivada com soja [Glycine $\max (\mathrm{L}$.) Merril] no verão anterior e azevém (Lolium multiflorum L.) no inverno. O experimento em monocultura foi conduzido em área mantida em pousio no inverno. Realizou-se a dessecação química das áreas 32 dias antes da semeadura. A semeadura foi nos dias 11 e 12 de outubro de 1998. As parcelas foram instaladas com espaçamento de $80 \mathrm{~cm}$ entre fileiras, com quatro linhas de $5 \mathrm{~m}$ perfazendo $12 \mathrm{~m}^{2}$. Num experimento estudou-se o efeito da rotação de culturas e no outro o da monocultura com as populações de 30, 40, 50, 60 e 70 mil plantas ha ${ }^{-1}$, observando- se o delineamento experimental de blocos ao acaso com quatro repetições. Na adubação de base, foi utilizada a fórmula 05$25-25$ (N-P-K), na quantidade de $300 \mathrm{~kg} \mathrm{ha}^{-1}$. A adubação nitrogenada de cobertura foi realizada com $290 \mathrm{~kg} \mathrm{ha}^{-1} \mathrm{de}$ uréia, parcelados aos 30 dias $(60 \%)$ e aos 45 dias (40\%) após a emergência. Utilizou-se o híbrido Pioneer 3071, cujas sementes foram tratadas com tiabendazol (40 g.i.a) mais captam (120 g.i.a/100 kg de sementes). Por sua vez, utilizouse como inseticida tiodicarb (300 g.i.a.), na dose de dois litros para cada $100 \mathrm{~kg}$ de sementes. A semeadura foi realizada com máquina manual colocando-se de duas a três sementes por cova. Realizou-se o desbaste das plantas aos 20 dias após a emergência, permanecendo uma planta por cova. Em 2 de novembro de 1998, aplicou-se inseticida deltametrina (50 g.i.a. $1^{-1}$ ) na dose de $1 \mathrm{ml} \mathrm{l}^{-1}$ de suspensão, para o controle da lagarta-do-cartucho do milho. Foram realizadas três irrigações durante os estádios fenológicos 4 a 6 , sendo a primeira no dia 25 de novembro com $7,85 \mathrm{~mm}$, a segunda no dia $1^{\circ}$ de dezembro com $16,65 \mathrm{~mm}$, e a terceira no dia 8 de dezembro com $31 \mathrm{~mm}$ de água, aproximadamente. O controle de invasoras foi realizado através de capina manual.

Para a quantificação da incidência e dos danos, a metodologia utilizada neste trabalho diferiu da de Nazareno (1989), que na quantificação dos danos nas lavouras amostradas, fixou a incidência em 50\% (utilizando 30 a 50 espigas de plantas sadias e igual número de espigas de plantas doentes). Neste trabalho, considerou-se a incidência real ocorrida na lavoura para a determinação de danos, utilizandose a metodologia desenvolvida por Reis et. al. (1998) e Denti et. al. (1999) para quantificar a incidência e os danos causados pelas $\mathrm{PBC}$ do milho. O procedimento consistiu em avaliar as duas fileiras centrais de cada parcela nos dois sistemas de cultivo, contando-se o número total de plantas, o número das plantas assintomáticas e o número das plantas com sintomas de PBC. As espigas foram colhidas separadamente para os dois grupos de plantas. Considerou-se planta sintomática aquela que apresentava descoloração do primeiro entrenó logo acima da superfície do solo e menor resistência à pressão dos dedos polegar e indicador. Da base dos colmos das plantas sintomáticas, foram cortados segmentos com 25 a $35 \mathrm{~cm}$ de comprimento a partir do nível do solo. Finalmente procedeuse a colheita das espigas/parcela e em grupos separados. Em laboratório, determinou-se a umidade dos grãos das espigas sintomáticas e assintomáticas. Em seguida, as espigas foram colocadas em casa de vegetação para redução da umidade. No momento em que os grãos apresentaram umidade em torno de $15 \%$, as espigas de plantas assintomáticas e sintomáticas foram debulhadas separadamente, utilizando-se um debulhador acionado por motor elétrico. Ao mesmo tempo, procedeu-se à limpeza dos grãos.

Para o cálculo do dano, utilizaram-se as seguintes fórmulas:a) desconto de umidade em $\%=100$ (Ui - Uf)/100 13 ; b) rendimento potencial $(R p)=(\mathrm{PGPA} / \mathrm{NPA}) \times \mathrm{NTP} ; \mathrm{c})$ rendimento real $(R r)=\mathrm{PGPA}+\mathrm{PGPS} ; \mathrm{d})$ o dano $(D)=\mathrm{Rp}-$ $\mathrm{Rr}$, sendo que $U i$ representa a umidade inicial ou de colheita; $U f$, a umidade final nos grãos a $13 \%$, utilizando-se a fórmula 
Efeito da rotação de culturas, da monocultura e da densidade...

relatada por Puzzi (1977); PGPA, o peso de grãos de plantas assintomáticas; NPA, número de plantas assintomáticas; NTP, número total de plantas em $10 \mathrm{~m}$ de fileira e PGPS, peso de grãos de plantas sintomáticas.

Para o cálculo da incidência (\%) das PBCs, utilizouse a fórmula: $I \%)=(\mathrm{NPS} / \mathrm{NTP}) \times 100$. Assim, NPS, número de plantas sintomáticas e NTP, número de plantas por fileira de $10 \mathrm{~m}$. Procedeu-se também ao isolamento dos fungos dos tecidos da base do colmo (primeiro entrenó longo acima da superfície do solo) de plantas sintomáticas para a identificação das espécies de fungos envolvidas no complexo das PBC nos experimentos. $\mathrm{O}$ meio nutritivo utilizado foi um quarto BDA (50 g de batata; $5 \mathrm{~g}$ de dextrose, $15 \mathrm{~g}$ de ágar e água destilada q.s.p. um litro).

\section{RESULTADOS E DISCUSSÃO}

Na última amostragem, a umidade média de grãos independentemente das densidades populacionais, foi de $19,4 \%$ na área de rotação de culturas e de $18,1 \%$ na área de monocultura.

Nos resultados do efeito da monocultura e da rotação de culturas sobre a incidência das PBC (Figura 1), os valores utilizados para a incidência e para o dano são os valores médios das quatro repetições. No sistema de rotação de culturas, observou-se que a incidência das PBC do milho aumentou com o aumento da densidade de plantas, sendo representada pela equação linear $I=-7,825+0,2953 \mathrm{~d}, R^{2}=$ 0,92 e $(P=0,0093)$. Por outro lado, o dano causado pelas PBC do milho no mesmo sistema de cultivo (Figura 2) não foi significativo estatisticamente com o aumento da densidade de plantas, sendo representado pela equação $D=-72,566+$ $3,8126 \mathrm{~d}, \mathrm{R}^{2}=0,62$ e $(P=0,112)$. Assim, neste sistema de cultivo, tanto a incidência $(12,9 \%)$ da doença como o dano (189 $\mathrm{kg} \mathrm{ha}^{-1}$ ) foram inferiores ao da área de monocultura. Mesmo na área com rotação de cultura, ocorreram as PBC. Levanta-se a possibilidade que o inóculo pode ter tido origem

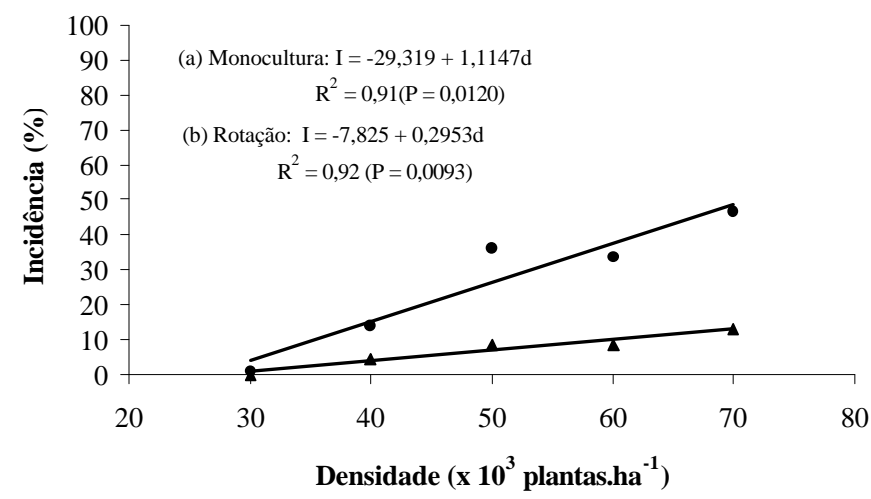

FIG. 1 - Efeito da densidade de plantas de milho (Zea mays) híbrido P3071 sobre a incidência das podridões da base do colmo sob monocultura e rotação de culturas ( $\mathrm{I}=$ =incidência e $\mathrm{d}=$ densidade de plantas). nas espécies vegetais presentes na área, no verão, como papuã [Brachiaria plantaginea (Link.) Hitch.] e milhã (Digitaria sanguinalis) e, no inverno, azevém. Através de isolamentos de tecidos da base do colmo do milho, as seguintes espécies de fungos, com a respectiva incidência, foram identificadas no experimento sob rotação de culturas:D. maydis $(3,4 \%)$, D. macrospora $(3,3 \%), F$. graminearum $(1,9 \%), F$. subglutinans $(0,4 \%), F$. moniliforme $(0,2 \%)$ e $F$. equiseti (Corda) Sacc. $(0,1 \%)$. Esses resultados levam a crer que as espécies de Fusarium, principalmente $F$. graminearum, possam ter tido como fonte de inóculo os restos culturais do azevém, papuã e milhã, os quais são hospedeiros secundários, conforme relatado por Reis (1990). Quantificaram-se 3.890 $\mathrm{kg} \mathrm{ha}^{-1}$ de restos culturais de azevém no momento da semeadura do milho.

Para as espécies de Diplodia, o inóculo, provavelmente, deve ter tido origem nos restos culturais de milho da safra anterior de verão presentes a uma distância de $16 \mathrm{~m}$ de uma das bordas do experimento. É possível que os conídios de Diplodia tenham sido transportados pelo vento a partir dessa fonte de inóculo próxima, pois segundo Del Rio \& Melara (1991), em seu trabalho, houve uma redução da incidência e da severidade da podridão da espiga de $60 \%$ a $5 \mathrm{~m}$ da fonte de inóculo e de $80 \%$ a 20 m (Deacon, 1988).

Pelos dados obtidos (Figura 1), observa-se que, à medida que a densidade de plantas aumentou, independentemente do sistema de cultivo (rotação ou monocultura), também aumentou na incidência das PBC do milho.

Provavelmente, o fator que determinou o aumento do dano esteja relacionado com a competição por água e nutrientes entre as densidades avaliadas, desequilíbrio nutricional entre colmos e espigas, conforme previamente sugerido por Zuber et al. (1957). Entretanto, outros autores também relatam que uma maior densidade de plantas (Machado, 1994; Agrios, 1997), aliada a um desequilíbrio nutricional, possa determinar uma maior predisposição das plantas às podridões do colmo (Shurtleff, 1992). A cultura manifestou sintomas de

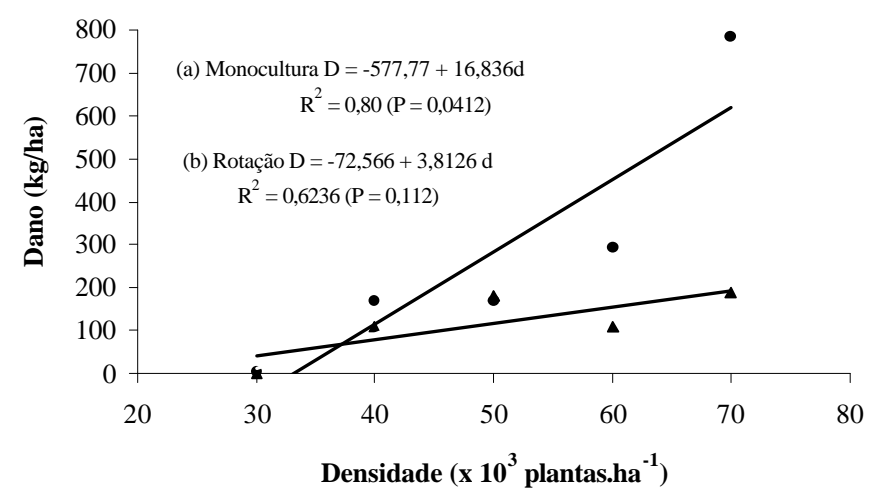

FIG. 2 - Efeito da densidade de plantas de milho (Zea mays) híbrido P3071 sobre os danos pelas podridões da base do colmo sob monocultura e rotação de culturas $(D=$ dano e $\mathrm{d}=$ densidade de plantas). 
deficiência hídrica, o que levou a que se realizassem três irrigações entre os estádios fenológicos 4 e 6, com a quantidade de 55,5 mm de água em ambos os experimentos. Assim, a disponibilidade de água para a translocação de nutrientes do solo e a redistribuição na planta, bem como a abertura dos estômatos para a realização da fotossíntese, possivelmente tenham sido insuficientes durante os estádios de crescimento e desenvolvimento da cultura, devido a estiagem ocorrida, resultando em menor acúmulo de carboidratos nos colmos das plantas, sobretudo nas parcelas de maior densidade (Fancelli, 1998). Assim, as menores densidades (30 mil plantas ha $^{-1}$ ) nos dois sistemas, monocultura e rotação, foram as que apresentaram as menores incidências, ao passo que as maiores densidades (70 mil plantas $\mathrm{ha}^{-1}$ ) resultaram nas maiores incidências das $\mathrm{PBC}$. O mesmo raciocínio provavelmente possa ser aplicado aos danos na área de monocultura. Deve-se ressaltar que, na área de monocultura, no momento da semeadura, foram quantificados $2.150 \mathrm{~kg}$ ha${ }^{1}$ de restos culturais de milho remanescentes da cultura anterior na superfície do solo. Esse fato, possivelmente, contribuiu para a maior incidência e dano nessa área.

Identificaram-se, das plantas sintomáticas, em monocultura, as seguintes espécies de fungos:D. maydis $(8,4 \%)$, D. macrospora $(4,9 \%), F$. graminearum (1,3\%), $F$. moniliforme $(0,8 \%), F$. subglutinans $(0,2 \%)$ e Bipolaris zeicola (Stout) Shoem $(0,08 \%)$. Portanto, a incidência média das espécies de fungos foi maior na área de monocultura, talvez pela maior pressão de inóculo presente na área, principalmente das espécies de Diplodia. Essa observação confirma relatos de Mora \& Moreno (1984), de que a incidência das podridões do colmo e da espiga causada por Diplodia spp. apresenta relação direta com a quantidade de restos culturais infetados presentes na superfície do solo e com taxa de sobrevivência e produção de inóculo (Snyman \& Wehner, 1988). Assim, os fungos são encontrados sobrevivendo saprofiticamente, fora do período de cultivo (Reis \& Casa, 1996; Casa, 1997), colonizando raízes, coroas, colmos, bainhas foliares, brácteas de espigas, ráquis, grãos e sementes, permanecendo na lavoura como micélio ou picnídios (Balmer \& Pereira, 1987; Del Rio \& Melara, 1991). Portanto, a presença dos restos culturais infetados assegura a presença dos patógenos na lavoura fato que deve ter contribuído para a ocorrência de maior incidência e dano em monocultura.

Com base na quantificação da incidência das PBC, dos danos e das espécies de fungos envolvidos nas PBC do milho, sugere-se que é mais conveniente estudar a incidência e os danos causados pelas PBC do milho em experimentos com inúmeros fatores que interagem com as $\mathrm{PBC}$ isoladamente. Tanto a rotação de culturas quanto a monocultura em sistema de semeadura direta e a densidade de plantas mostraram efeitos sobre a incidência e danos das PBC. Assim, confirma-se que as PBC do milho podem ser manejadas pela rotação de culturas e população de plantas. Foram várias as espécies de fungos envolvidos nas PBC, destacando-se com maior incidência $D$. maydis, seguida de $D$. macrospora, tanto para a área de rotação como para a de monocultura.

\section{REFERÊNCIAS BIBLIOGRÁFICAS}

AGRIOS, G.N. Plant Pathology. New York: Academic Press, 1997.

BALMER, E. \& PEREIRA, O.A.P. Doenças do milho. In:Paterniani, E. \& Viégas, G.P. (Eds.) Melhoramento e produção do milho. 2.ed. Campinas, Fundação Cargill, 1987. pp. 595-634.

BRASIL. Ministério da Agricultura. Departamento Nacional de Pesquisa Agropecuária. Divisão de pesquisa pedológica. Levantamento de reconhecimento dos solos do Estado do Rio Grande do Sul. Recife, DNPEA, Boletim Técnico, n.30. 1973.

BYRNES, K.L. \& CARROL, R.B. Fungi causing stalk rot of conventional-tillage and no-tillage corn in Delaware. Plant Disease 70:238. 1986.

CASA, R.T. Diplodia maydis e D. macrospora associadas à semente de milho. (Dissertação de Mestrado) Viçosa, Universidade Federal de Viçosa. 1997.

CHRISTENSEN, J.J. \& WILCOXSON, R.D. Stalk rot of corn. St. Paul, MN. Americam Phytopathological Society, 1966.

DEACON, J.M. Introducion a la micologia moderna. México. Limusa, 1988.

DEL RIO, L. \& MELARA, W. Dispersion de Stenocarpella maydis (Berk.) Sutton en un cultivo de maiz. Ceiba 32:133-140. 1991.

DEL RIO, L. \& ZÚNGIA, T. Efecto de algunas practicas culturales y fechas de recoleccion en la incidencia de Stenocarpella maydis (Berk.) Sutton en maiz sembrado en dos sistemas de labranza. Ceiba 32:141-149. 1991.

DENTI, E.A., TRENTO, S.M, \& REIS, E.M. Incidência, freqüência e danos por fungos envolvidos com as podridões da base do colmo do milho em 1997/98, nas regiões do Planalto Médio Gaúcho (RS) e de Guarapuava (PR). Fitopatologia Brasileira 24:279. 1999 (Resumo).

EMBRAPA-CNPT. Informações Meteorológicas/Embrapa Trigo. Disponível na internet. http://www.cnpt.embrpa. br/agromet.htlm. 4 janeiro. 2000.

FANCELLI, A.L. Fenologia do milho. Disponível na Internt. http//www.faeg.com.br/fenologi.html. 18 abril 1998.

FUNDAÇÃO ESTADUAL DE PESQUISA AGROPECUÁRIA; ASSOCIAÇÃO DE EMPREENDIMENTO DE ASSISTÊNCIA TÉCNICA E EXTENSÃO RURAL; FEDERAÇÃO DAS COOPERATIVAS DE TRIGO E SOJA DO RS LTDA. Recomendações técnicas para a cultura do milho no Estado do Rio Grande do Sul. Porto Alegre, FEPAGRO, Boletim Técnico, 6. 1999.

MACHADO, J.C. Padrões de tolerância de patógenos associados à sementes. In:Luz, W.C., Fernandes, J.M.C., Prestes, A.M. \& Picinini, D.C. (Eds.). Revisão Anual de Patologia de Plantas 4:229-263. 1994.

MORA, L.E. \& MORENO, R.A. Cropping pattern and soil management influence on plant diseases:I. Diplodia macrospora leaf spot of maize. Turrialba 34:35-40. 1984.

NAZARENO, N.R.X. Avaliação de perdas por podridão do 
Efeito da rotação de culturas, da monocultura e da densidade...

colmo em milho (Zea mays) no Estado do Paraná. Fitopatologia Brasileira 14:82-84. 1989.

PEREIRA, O.A.P. \& PEREIRA, W.S.P. Estudo de Diplodia zeae (Shw) Lev. e Fusarium moniliforme Sheld. em colmo de milho. Summa Phytopathologica 2:165-171. 1976.

PUZZI, D. Manual de armazenamento de grãos:armazéns e silos. São Paulo:Agronômica Ceres, 1977.

REIS, E.M. Perithecial formation of Gibberella zeae on senescent stems of grasses under natural conditions. Fitopatologia Brasileira 15:52-53. 1990.

REIS, E.M. \& CASA, R.T. Manual de identificação e controle de doenças de milho. Passo Fundo:Aldeia Norte Editora. 1996.
REIS, E.M., DENTI, E.A., TRENTO, S.M., CASA, R.T. \& SEVERO, R. Método para quantificar os danos no rendimento de grãos causados pelas podridões da base do colmo do milho. Fitopatologia Brasileira 23:300. 1998 (Resumo).

SHURTLEFF, M.C. Compendium of Corn Diseases. St $\mathrm{t}^{\mathrm{a}}$. Paul:American Phytopathological Society,1992. 105p.

SNYMAN, A.J. \& WEHNER, F.C. Effect of environmental factors on inoculum production by Stenocarpella maydis. Phytophylactia 20:106. 1988. (Abstract).

ZUBER, M.S., CROGAN, G.O. \& MICHELSON, M.E. Studies of the interrelation of tild stalk lading, two stalk rotting fungi, and chemical composition of corn. Agronomy Journal 49:328-331. 1957. 